Semiannual Technical Report to DOE - PETC - Grant \# DE-FG22-96PC96205--05 9/1/98-3/1/99

\title{
COAL AND COAL CONSTITUENTS STUDIES BY ADVANCED EMR TECHNIQUES
}

\author{
by R. Linn Belford, Robert B Clarkson, and Boris M. Odintsov
}

University of Illinois at Urbana-Champaign

\begin{abstract}
DISCLAIMER
This report was prepared as an account of work sponsored by an agency of the United States Government. Neither the United States Government nor any agency thereof, nor any of their employees, makes any warranty, express or implied, or assumes any legal liability or responsibility for the accuracy, completeness, or usefulness of any information, apparatus, product, or process disclosed, or represents that its use would not infringe privately owned rights. Reference herein to any specific commercial product, process, or service by trade name, trademark, manufacturer, or otherwise does not necessarily constitute or imply its endorsement, recommendation, or favoring by the United States Government or any agency thereof. The views and opinions of authors expressed herein do not necessarily state or reflect those of the United States Government or any agency thereof.
\end{abstract}

\section{ABSTRACT}

Advanced magnetic resonance (EMR) methods are used to examine properties of coals, chars, and molecular species related to constituents of coal. During this grant period, further progress was made on proton NMR and low-frequency dynamic nuclear polarization (DNP) to examine the interaction between fluids such as water and the surface of suspended char particles. Effects of char particle size and type on water nuclear spin relaxation, T2, were measured and modeled.

\section{TABLE OF CONTENTS}

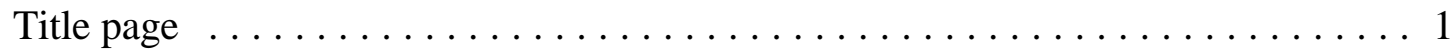

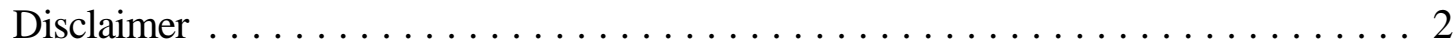

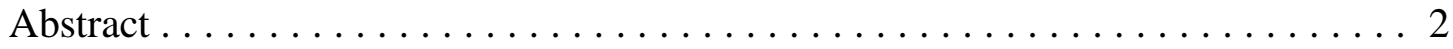

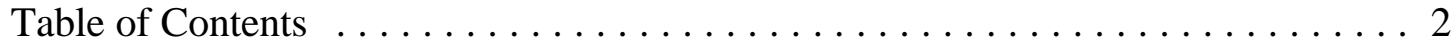

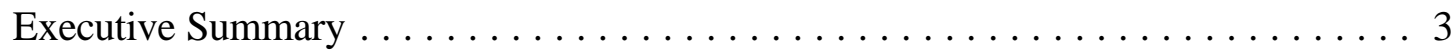

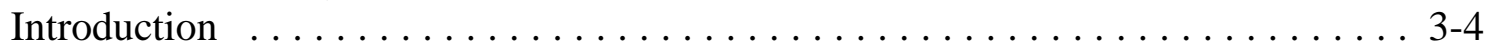

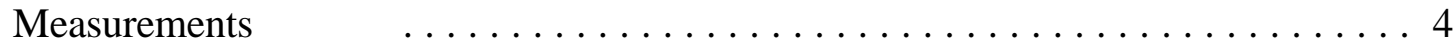

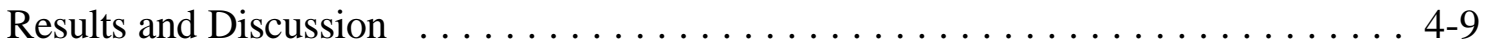

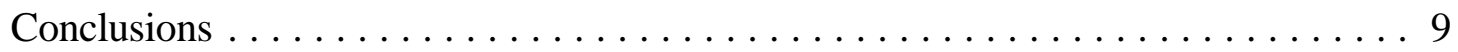

References .............................. 10 
Semiannual Technical Report to DOE - PETC - Grant \# DE-FG22-96PC96205 9/1/98-3/1/99

\section{EXECUTIVE SUMMARY}

The main advanced magnetic resonance methods employed in this project are (1) very low frequency pulsed dynamic nuclear polarization (DNP) spectroscopy for the study of the interfaces between coal-like particles and the water medium in which they are suspended, (2) Wband $(100 \mathrm{GHz})$ electronic magnetic resonance (EMR, EPR, or ESR) spectroscopy to provide an analytical tool to discriminate among very similar chemical species that are constituents of coals and closely related materials such as chars, and (3) a variety of proton nuclear magnetic resonance (NMR) techniques to measure characteristics of the water in contact with the particle surfaces and pore spaces. As detailed in previous semiannual progress reports to DOE, DNP behavior has revealed a transient chemisorption of water molecules on the external surfaces and/or pore walls of carbon char particles manufactured from particular wood precursors in highly controlled pyrolyses.

The current report describes the second part of a study of NMR relaxation of water protons in char particles suspended in water. In the first part of this study (see the previous semiannual report), a strong particle size influence on NMR transverse proton relaxation in aqueous suspensions of several newly synthesized carbon based chars was found. The current report describes new supporting experiments and a model that help interpret these findings. The main conclusions include these: The dependence of the transverse relaxation of water protons on particle size in these suspensions of several newly synthesized carbon based chars can be interpreted quantitatively in terms of a two-stage molecular exchange model. A porous cage effect leads to slow exchange between molecules inside and outside pores in contrast to fast molecular exchange processes at the solid-liquid interface, where the usual two-site formalism can be applied. Owing to increasing surface-to-volume ratio, the corresponding transverse relaxation times of water protons in aqueous char suspensions are shortened as the size decreases. Surface properties strongly effects the relaxation times. The more the hydrophilic character of the surface, the shorter the relaxation times at the solid-liquid interface. The strong particle size effect on the transverse relaxation time of solvent protons seen in char suspensions makes possible the rapid and easy measurement of relative particle sizes in different kinds of suspensions by an NMR pulsed technique.

\section{INTRODUCTION}

As described in Part I of this study [1], an understanding of intermolecular interactions and molecular motion at the solid-liquid interface is of central importance to research concerning heterogeneous catalysis, fluid penetration of engineering plastics and ceramics, and biological perfusion. Studies of molecular diffusion and relaxation processes in paramagnetic porous materials provide valuable information about surface relaxivity and spin dynamics at the solidliquid interface [2]. Over the past two decades, many different magnetic resonance methods have 
been used in studies of paramagnetic centers in carbonaceous solids as well as in studies of the surface diffusion of solvents adsorbed on charcoals [2-8]. EPR spectroscopy has shown that unpaired electrons responsible for the paramagnetism of chars exist in stable organic free radicals created during the heat-treatment carbonization [2,3]. Surface diffusion of solvents adsorbed on charcoals already has been the subject of NMR relaxation studies [4-6]. An NMR chemical shift technique also has been applied to study the molecules adsorbed on charcoal and silica gel $[7,8]$. Self-diffusion coefficients in porous media, measured by different kinds of Pulsed-Field-Gradient NMR, have been the object of intensive theoretical and experimental studies [9-13]. In spite of significant progress in these studies, the electronic structure of char paramagnetic centers and the process of free radical formation during carbonization, as well as the state of water at the paramagnetic surface, are not yet fully understood. So far, no theoretical calculation related to the electronic structure has been carried out for carbon based chars. Part I [1] described NMR relaxation time experiments designed to improve our systematic state of knowledge of chars, coals, and similar carbon-based materials in water suspensions. Findings are summarized in Table 1, reproduced below. The current report, Part II, describes a model and additional experiments helping to interpret and draw several conclusions from these findings.

\section{MEASUREMENTS}

The NMR relaxation measurement procedures are described in Part I [1]. The materials studied were samples of chars produced by a controlled low-temperature pyrolysis of carbonaceous materials, including hardwood, starch, and fructose, under $\mathrm{H}_{2}$ flow. The procedures are detailed in Part I [1]. DNP measurement procedures are described in previous reports. In tests for effects by soluble paramagnetic species that might exist in the chars, char particle suspensions were leached in pure water for several hours, the water was extracted, and NMR proton relaxation times measured to compare with those of the original pure water and of the water in the char suspensions.

\section{RESULTS and DISCUSSION}

The chars used in this study have a well-developed porous structure, leading to multiexponential NMR magnetization decays and several relaxation times. Spin-echo decay analysis shows the presence of two basic components [1] with different relaxation times that represent more than $90 \%$ of all water molecules in the sample. One of them represents $2-9 \%$ of water molecules, has comparatively short relaxation times $\mathrm{T}_{\mathrm{p}} \approx 3-10 \mathrm{~ms}$, and demonstrates a weak char particle size dependence. This component can be attributed to the water molecules mainly in pore spaces where they are undergoing restricted diffusion and multiple collisions with the paramagnetic walls in a porous cage [22]. High resolution proton NMR usually fails to observe this component. The porous cage effect leads to a slow exchange process between molecules inside and outside the porous structure. Another relaxation component represents $80-85 \%$ of 
water molecules in char suspensions, and has much longer $T_{2}$ relaxation times, as well as a strong char particle size dependence (see Table 1, reproduced from Part I [1]).

Table 1. Observed Proton Transverse Relaxation Time $\left(\mathrm{T}_{2}\right)_{\mathrm{obsd}, \mathrm{i}}$ (in sec) as a Function of $180^{\circ}$ Pulse Interval in CPMG Sequence $\tau$ in Aqueous Char Suspensions Reproduced from reference [1].

\begin{tabular}{|c|c|c|c|c|c|c|}
\hline \multirow{2}{*}{ No. $\begin{array}{l}\text { larar } \\
\text { particle } \\
\text { size } \\
(\mu \mathrm{m})\end{array}$} & \multicolumn{5}{|c|}{$\tau, \mathrm{ms}$} \\
\cline { 3 - 7 } & 0.2 & 1.0 & 2.0 & 5.0 & 10.0 \\
\hline 1 & $850 \pm 170$ & $0.743 \pm 0.04$ & $0.722 \pm 0.04$ & $0.754 \pm 0.04$ & $0.741 \pm 0.04$ & $0.720 \pm 0.04$ \\
\hline 2 & $450 \pm 90$ & $0.632 \pm 0.03$ & $0.624 \pm 0.03$ & $0.636 \pm 0.03$ & $0.651 \pm 0.03$ & $0.648 \pm 0.03$ \\
\hline 3 & $250 \pm 50$ & $0.470 \pm 0.02$ & $0.495 \pm 0.03$ & $0.467 \pm 0.02$ & $0.432 \pm 0.02$ & $0.461 \pm 0.02$ \\
\hline 4 & $100 \pm 20$ & $0.208 \pm 0.01$ & $0.210 \pm 0.01$ & $0.202 \pm 0.01$ & $0.213 \pm 0.01$ & $0.196 \pm 0.01$ \\
\hline 5 & $50 \pm 10$ & $0.100 \pm 0.005$ & $0.087 \pm 0.005$ & $0.079 \pm 0.004$ & $0.086 \pm 0.004$ & $0.086 \pm 0.005$ \\
\hline
\end{tabular}

It was important to test whether the shortening of the relaxation times in char suspensions could have been caused by any soluble paramagnetic ions or free radicals from the particulates. Therefore, the sample chars were leached in pure $\mathrm{H}_{2} \mathrm{O}$ for several hours, followed by $\mathrm{H}_{2} \mathrm{O}$ extraction. The relaxation times of this extract were even longer by $7-10 \%$ than in pure water! The fact that proton relaxation in the extract was no faster than in pure water implies that there were essentially no easily soluble paramagnetic species in the char samples. The slight slowing of proton relaxation in the extract suggests at least two possibilities: (1) that the char worked as an absorbent, removing residual paramagnetic materials existed in the distilled water used in these experiments, or (2) that it had some other small chemical effect, such as a change in $\mathrm{pH}$.

The simple two-stage exchange model shown in Fig. 1 is invoked as a basis to account for the observations reported in Table 1 . It has been clearly shown [11-13, 17] that the relaxation times of solvent nuclei decrease as the surface-to-volume ratio for solids increases, which is a result of the fact that the solvent molecules near the surface have different properties from those in the bulk phase. Usually the solvent molecules at the surface layer undergo more restricted motion as well as faster electron-nuclear relaxation due to the presence of free radicals in chars; there is a gradual change in physical properties of the solvent molecules at the surface to those in the bulk phase as the distance from the surface increases. Exchange processes between solvent molecules at the surface as well as fast molecular motion are responsible for this gradual 


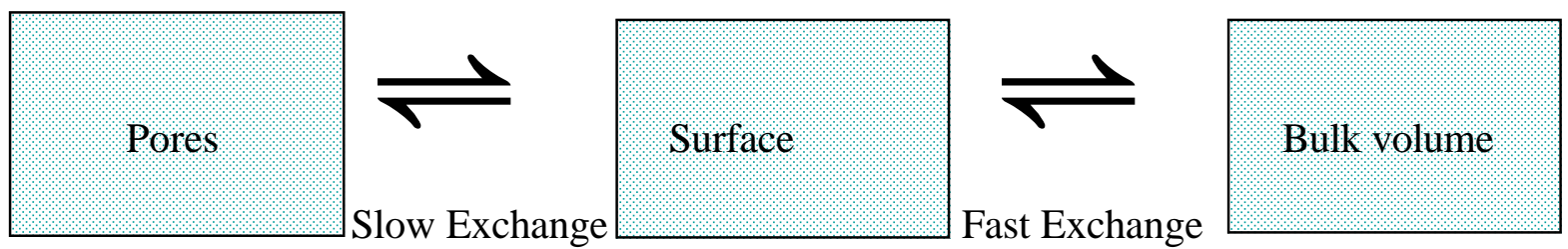

Figure 1. Schematic illustrating the existence of two basic components in transverse NMR relaxation of water protons in char suspensions. Porous cage effect leads to slow exchange between molecules inside and outside pores, in contrast to fast molecular exchange process at solid-liquid interface.

change of solvent properties. The intensity of exchange as well as the direct influence of the surface on $\mathrm{T}_{2}$ can strongly be affected by the character of the char surface $[21,22]$.

The systems under study can be described by the following equation [23]:

$$
\left(\mathrm{T}_{2}^{-1}\right)_{\mathrm{obsd}, \mathrm{i}}=\mathrm{P}_{\mathrm{s}, \mathrm{i}} / \mathrm{T}_{2 \mathrm{~s}}+\mathrm{P}_{\mathrm{b}, \mathrm{i}} / \mathrm{T}_{2 \mathrm{~b}}
$$

where $\left(\mathrm{T}_{2}{ }^{-1}\right)_{\text {obsd, }}$ is the experimentally observed relaxation time of the sample with a particle size $i$ (see Table 1); $\mathrm{P}_{\mathrm{s}, \mathrm{i}}$ and $\mathrm{P}_{\mathrm{b}, \mathrm{i}}$ are the probabilities that the exchanging molecules are on the surface and in the bulk water, with relaxation times $T_{2 s}$ and $T_{2 b}$, respectively. Taking into account that $P_{b, i}$ $=1-\mathrm{P}_{\mathrm{s}, \mathrm{i}}$, one can represent formula (1) in the form

$$
\left(\mathrm{T}_{2}{ }^{-1}\right)_{\mathrm{obsd}, \mathrm{i}}=\mathrm{P}_{\mathrm{s}, \mathrm{i}}\left(\mathrm{T}_{2 \mathrm{~s}}{ }^{-1}-\mathrm{T}_{2 \mathrm{~b}}{ }^{-1}\right)+\mathrm{T}_{2 \mathrm{~b}}{ }^{-1}
$$

Since $\mathrm{P}_{\mathrm{s}, \mathrm{i}}$ is proportional to the total surface area of particles in the sample of size $i$, equation (2) can be expressed as a function of particle dimensions.

Let us assume that particles with average linear dimension $\mathrm{R}_{\mathrm{i}}$ occupy a volume $\mathrm{V}$ with a filling coefficient $k$, and that the volume of each particle is equal to $\eta \mathrm{R}_{\mathrm{i}}{ }^{3}$, where $\eta$ is the volumetric coefficient of particle shape. In this case the total number of particles $\mathrm{N}_{\mathrm{i}}$ in the volume $\mathrm{V}$ will be equal to

$$
\mathrm{N}_{\mathrm{i}}=k \mathrm{~V} / \eta \mathrm{R}_{\mathrm{i}}^{3}
$$

The surface area of each particle can be represented by $\theta \mathrm{R}_{\mathrm{i}}^{2}$, where $\theta$ is surface area coefficient of particle shape. Now one can calculate the total surface area of $\mathrm{N}_{\mathrm{i}}$ particles in the volume $\mathrm{V}$ :

$$
\mathrm{N}_{\mathrm{i}} \times \theta \mathrm{R}^{2}=k \theta \mathrm{V} / \eta \mathrm{R}_{\mathrm{i}}
$$

If water occupying volume $\mathrm{V}(1-k)$ in char suspensions creates a layer of thickness $h$ on the surface of each char particle, then the volume $\mathrm{V}_{\mathrm{s}, \mathrm{i}}$ of such a layer can be estimated by the formula 
Semiannual Technical Report to DOE - PETC - Grant \# DE-FG22-96PC96205 9/1/98-3/1/99

$$
\mathrm{V}_{\mathrm{s}, \mathrm{i}}=k \theta h \mathrm{~V} / \eta \mathrm{R}_{\mathrm{i}}
$$

In this case, the relative fraction of the molecules in the surface water layer (and the probability that the exchanging water molecules are on the surface) is expressed by

$$
\mathrm{P}_{\mathrm{s}, \mathrm{i}}=\mathrm{V}_{\mathrm{s}, \mathrm{i}} / \mathrm{V}(1-k)=k \theta h / \eta(1-k) \mathrm{R}_{\mathrm{i}}
$$

Now formula (2) can be represented in the form

$$
\left(\mathrm{T}_{2}{ }^{-1}\right)_{\text {obsd, } \mathrm{i}}=\left(\mathrm{R}_{1} / \mathrm{R}_{\mathrm{i}}\right) \mathrm{P}_{\mathrm{s}, 1}\left(\mathrm{~T}_{2 \mathrm{~s}}{ }^{-1}-\mathrm{T}_{2 \mathrm{~b}}{ }^{-1}\right)+\mathrm{T}_{2 \mathrm{~b}}{ }^{-1}
$$

where $R_{1}$ is the average dimension of a reference particle, and $P_{s, 1}$ is the fraction of surface water associated with the reference sample. A particle of any size can be taken as a reference, and in this analysis we used the largest particle size (see Table 1).

Equation (7) indicates that the $\left(\mathrm{T}_{2}{ }^{-1}\right)_{\text {obsd, } \mathrm{i}}$ is a linear function of $\left(\mathrm{R}_{1} / \mathrm{R}_{\mathrm{i}}\right)$ with a slope of $\mathrm{P}_{\mathrm{s}, \mathrm{T}} \mathrm{T}_{2 \mathrm{~s}}{ }^{-1}$, if for simplicity one takes into account that the relaxation time on the paramagnetic surface $T_{2 s}$ is much shorter than $T_{2 b}$ in bulk water. Figure 2 shows a plot of $\left(T_{2}{ }^{-1}\right)_{o b s d}$ for hardwood char suspensions as a function of the ratio of the sample particle dimensions; it is in good agreement with formula (7). In accordance with (7) the curve passes through $T_{2 b}$ at

$\mathrm{R}_{1} / \mathrm{R}_{\mathrm{i}}=0$, and the fitting procedure gives a reasonable value of the

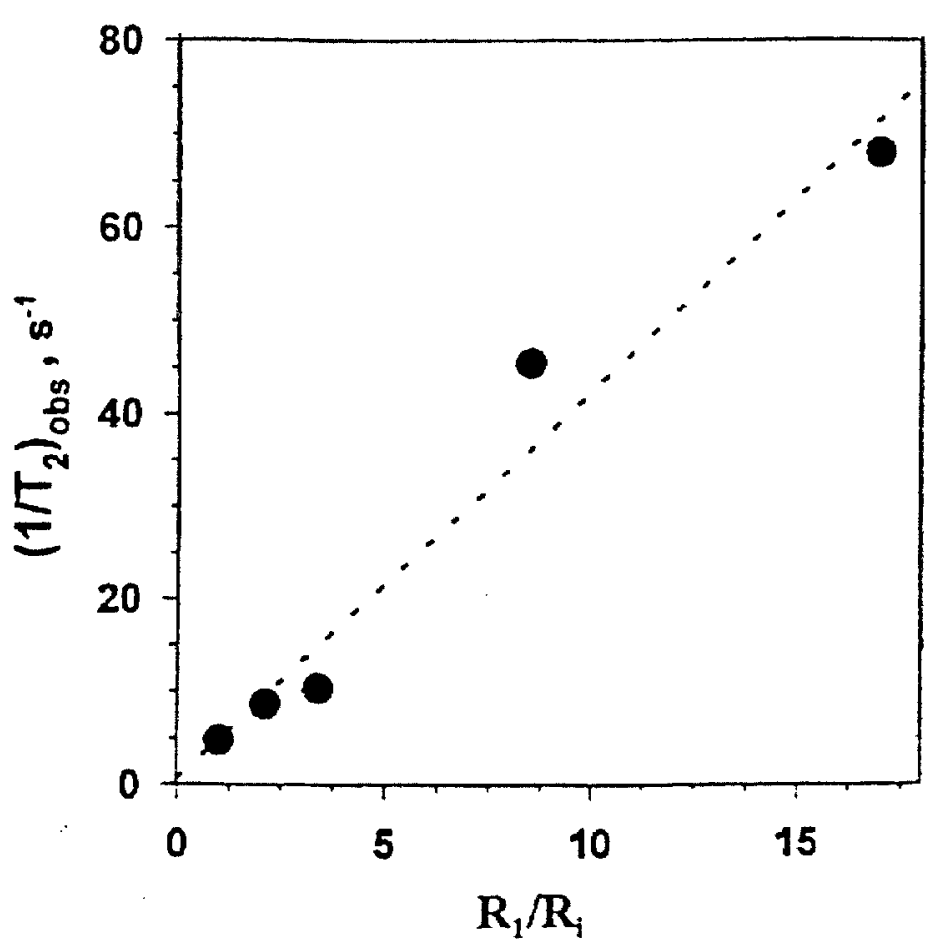

Fig. 2. Observed transverse relaxation rate of water protons as a function of particle size in hardwood char suspensions. relaxation time in bulk water, $\mathrm{T}_{2 \mathrm{~b}}$ $\approx 2 \mathrm{~s}$, which is close to the corresponding relaxation time of the distilled water $(2.3 \mathrm{~s})$ used in these experiments.

Using Eqs. (6) and (7), one can estimate the relaxation time $T_{2 \mathrm{~s}}$ of water protons on the paramagnetic surface of chars according to the following expression

$$
\begin{aligned}
\mathrm{T}_{2 \mathrm{~s}}{ }^{-1}= & {\left[\left(\mathrm{T}_{2}{ }^{-1}\right)_{\text {obsd, } \mathrm{i}}-\mathrm{T}_{2 \mathrm{~b}}{ }^{-1}\right] \mathrm{R}_{\mathrm{i}} \eta \times } \\
& \times(1-k) / k \theta h+\mathrm{T}_{2 \mathrm{~b}}{ }^{-1}(8)
\end{aligned}
$$

The volumetric concentration $0.82 \pm 10 \% \mathrm{~g} / \mathrm{cm}^{3}$ of char particles in suspensions was used in these experiments, which means that the coefficient $k$ in (8) is 0.82 . Because all samples were ground by agate mortar to avoid orientational effects due to possible needle 
shapes, it is reasonable to assume that the particle shape is close to spherical, which leads to well known ratio for spheres:

$$
\theta / \eta=4 \pi /(4 \pi / 3)=3
$$

A rough and ready estimate of the thickness $h$ of the water layer closest to the char particle surface is chosen commensurate with the dimension of a water molecule $h \approx(2 \times 1.5) \AA$. With these assumptions, calculations give the water proton relaxation time on the paramagnetic surface of chars as $\mathrm{T}_{2 \mathrm{~s}} \approx 0.5 \times 10^{-5} \mathrm{~s}$, which is comparable to the electron relaxation time, $1.5 \times 10^{-6}$ $\mathrm{s}(300 \mathrm{~K})$, that we previously measured [21] for free radical paramagnetic centers in hardwood chars.

The deviation of char particle shape from spherical to elongated needle results in a gradual decrease of water proton relaxation time $\mathrm{T}_{2 \mathrm{~s}}$ at the surface. Calculations show that an increase of the length of the char needles (micro cylinders) by $20 \%$ leads to a $\mathrm{T}_{2 \mathrm{~s}}$ decrease of $6 \%$.

Using a CPMG pulse sequence, we measured $\mathrm{T}_{2}$ as a function of the $180^{\circ}$ pulse period $\tau$, but observed only a little variation of $\mathrm{T}_{2}$ with $\tau$ over the range mentioned in the previous section (Table 1). It is well known [11] that the magnitude of the nuclear spin transverse relaxation time $\left(\mathrm{T}_{2}\right)$ in solutions is decreased by molecular diffusion in the inhomogeneous magnetic fields created by an applied external magnetic field or by microscopic heterogeneity in the sample. The system described is a heterogeneous one; therefore, there is good reason to observe a diffusion effect in $\mathrm{T}_{2}$ measurements by the spin-echo technique. The small variation of $\mathrm{T}_{2}$ seen at widely different pulse intervals in the CPMG sequence can be explained by a mechanism suggested by Hills et al. in [24]. They showed that if relaxation on the solid-liquid interface was short enough, the following condition is fulfilled,

$$
\left(\mathrm{T}_{2}^{-1}\right)_{\text {Surface }}>|\Delta \mathrm{v}|
$$

where $\Delta v$ is the isotropic Knight shift of the water protons on the paramagnetic surface. Under these conditions, the observed transverse relaxation time should not depend on the pulse interval $\tau$. This is in fact what we observed for the hardwood char system.

Recently, we showed that aqueous suspensions of hardwood chars studied in this work exhibited a positive Dynamic Nuclear Polarization (DNP) effect [25].This is strong evidence for the presence of an electron-nuclear Fermi contact interaction at the solid-liquid interface. The contact interaction demonstrated for the first time that there is electron delocalization from paramagnetic centers on the char surface to water protons in the solvent, since the contact interaction demands that there be a non-zero value for the electronic wave function at the nucleus [26]. The value of the intermolecular hyperfine contact constant $a \approx 6 \times 10^{-3} \mathrm{MHz}$ at the surface of chars was determined in our work [21] by means of a DNP technique at low magnetic fields. The corresponding paramagnetic shift can be calculated with the following formula [23]:

$$
\Delta v=-a v_{\mathrm{N}} \mathrm{g} \beta \mathrm{S}(\mathrm{S}+1) /\left(\mathrm{g}_{\mathrm{N}} \beta_{\mathrm{N}} 3 \mathrm{kT}\right)
$$

where $v_{N}$ is the proton resonance frequence, $S$ is the electron spin value $(S=1 / 2)$ and the other 
parameters have their usual meaning. Calculations for $v_{\mathrm{N}}=6 \mathrm{MHz}$ give $\Delta v \approx 23 \mathrm{~Hz}$ providing that condition (10) is fulfilled. It should be noted that the corresponding line is not observed in high resolution NMR spectra because of the fast proton relaxation of water molecules on the paramagnetic surface of chars.

Finally, it should be noted that the relaxation data demonstrated a strong dependence on surface properties. Table 2 shows the dependence of $\left(\mathrm{T}_{2}\right)_{\text {obsd }}$ for water protons in char suspensions prepared from different starting materials. Each sample was prepared under similar thermal treatment conditions and sieved to the same particle size $(50 \mu \mathrm{m})$. In accordance with our observations in [22] the data indicate that the more hydrophilic character of hardwood chars (in compare with starch and fructose) leads to shorter transverse relaxation times at the solid-liquid interface.

Table 2. $\left(\mathrm{T}_{2}\right)_{\text {obsd }}$ of Water Protons in Aqueous Char Suspensions for Different Starting Carbonaceous Materials

\begin{tabular}{|c|c|}
\hline Material & $\left(\mathbf{T}_{2}\right)_{\text {obsd }}, \mathbf{S}$ \\
\hline Hardwood & $\mathbf{0 . 1 0 0} \pm 005$ \\
\hline Starch & $\mathbf{0 . 1 8} \pm \mathbf{0 . 0 1}$ \\
\hline Fructose & $\mathbf{0 . 5 3} \pm \mathbf{0 . 0 3}$ \\
\hline
\end{tabular}

\section{CONCLUSIONS}

1. The dependence of the transverse relaxation of water protons on particle size in aqueous suspensions of several newly synthesized carbon based chars can be interpreted quantitatively in terms of a two-stage molecular exchange model. A porous cage effect leads to slow exchange between molecules inside and outside pores in contrast to fast molecular exchange processes at the solid-liquid interface, where the usual two-site formalism can be applied. Owing to increasing surface-to-volume ratio, the corresponding transverse relaxation times of water protons in aqueous char suspensions are shortened as the size decreases.

2. Surface properties strongly effects the relaxation times. The more the hydrophilic character of the surface, the shorter the relaxation times at the solid-liquid interface.

3 . The transverse NMR relaxation time of water protons on the paramagnetic surface of chars $\mathrm{T}_{2 \mathrm{~s}}=0.5 \times 10^{-5} \mathrm{~s}(300 \mathrm{~K})$ is comparable the with EPR relaxation time of free radical paramagnetic centers in the char.

4. The paramagnetic shift $\Delta v$ of water protons on the surface of chars is much less than their transverse NMR relaxation rate on the surface; $|\Delta v|<<\mathrm{T}_{2 \mathrm{~s}}{ }^{-1}$. The inequality is responsible for the independence of the NMR transverse relaxation times on the interval $\tau$ in the CPMG pulse sequence used in these experiments.

5. The strong particle size effect on the transverse relaxation time of solvent protons seen in char suspensions makes possible the rapid and easy measurement of relative particle sizes in different kinds of suspensions by an NMR pulsed technique. 
Semiannual Technical Report to DOE - PETC - Grant \# DE-FG22-96PC96205 9/1/98-3/1/99

\section{REFERENCES}

(Combined references for Part I and Part II)

1. R.L. Belford, R.B. Clarkson, B.M. Odintsov, Fourth Semiannual Report to DOE-PETC for Grant \# DE-FG22-96PC96205, October 1 (1998).

2. a. K.S. Rothenberger, R.F. Sprecher, S.M. Gastellano, H.L. Retcofsky, in Botto R.B. and Sanada Y. (Eds.),Advances in Chemistry, Am. Chem. Soc., Washington, DC, 1981, pp. 581-598.

b. H.L. Retcofsky, M.R. Hough, M.M. Maguire, R.B. Clarkson, in M.L. Golbaty and K. Ouchi, (Eds.) Advances in Chemistry, Am. Chem. Soc., Washington, DC, 1981, pp.37-53.

3. F.P.Auteri, R.L. Belford and R.B. Clarkson, Appl.Magn.Res., 6 (1994) 287.

4. H.A. Resing, Adv. Mol. Relax. Proc., 1 (1967-68) 109.

5. J.K. Thompson, J.J. Krebs and H.A. Resing, J.Phys.Chem. 43 (1965) 3853.

6. H.A.Resing, J.K. Thompson and J.J. Krebs, J.Phys.Chem., 68 (1964) 1621.

7. S. Kaplan, H.A. Resing and A. Waugh, J. Chem. Phys., 59 (1973) 5681.

8. E.G. Derouane, J. Fraissard, J.J. Fripiat and W.E.E. Stone, Catal. Rev., 7 (1972) 121.

9. P.T.Callaghan, A.Coy, D.MacGowan, K.J.Packer and F.O.Zelaya, Nature, 351 (1991) 467.

10. B.Antalek and K.Chari, Mod. Phys. Lett. B, 9 (1995) 155.

11. C.S.Johnson, Jr., in D.M.Grant and R.K. Harris (Eds.),Encyclopedia of NMR, Wiley: New York 1996, pp.1626-1644.

12. M.D.Hurlimann, K.G.Helmer, L.L.Latour and C.H.Sotak, J.Magn.Res., A, 111 (1994) 169.

13. P.P.Mitra, L.L.Latour, R.L.Kleinberg and C.H.Sotak, J.Magn.Reson., 114 (1995) 47 .

14. J.R.Zimmerman and W.E.Brittin, J.Phys.Chem., 61 (1957) 1328.

15. J.A.Glasel and K.H.Lee, J.Am.Chem.Soc., 96 (1974) 970.

16. R.L.Kleinberg and M.A.Horsfield, J.Magn.Reson., 88 (1990) 9.

17. P.T. Callaghan, "Principles of Nuclear Magnetic Resonance Microscopy", Oxford: Clarendon, 1991.

18. J.H.Strange, M.Rahman and E.G.Smith, Phys.Rev.Lett., 71 (1993) 3589.

19. Z.Sh. Idiatullin, A.N. Temnikov and R.S. Kashaev, Prib. i Techn. Experimenta, 5 (1992) 46.

20. S. Boyer and R.B. Clarkson, Coll. Surf., A. 82 (1994) 217.

21. B.M.Odintsov, R.L.Belford, P. J.Ceroke and R.B.Clarkson, Surf. Sci., 393 (1997) 162.

22. B.M.Odintsov, A.N.Temnikov, Z.Sh.Idiyatullin, R.S.Kashaev, R.L.Belford, P.J.Ceroke and R.B.Clarkson, J.Magn.Reson., in press, (1998).

23. A.Carrington, A.D.McLachlan, Introduction to Magnetic Resonance, Chapman and Hall, New York, 1980.

24. B.P.Hills, C.Cano and P.S.Bolton, 24 (1991) 2944.

25. B.M.Odintsov, R.L.Belford, P. J.Ceroke and R.B.Clarkson, J. Am. Chem. Soc. 120 (1998) 1076.

26. A. Abragam, Principles of Nuclear Magnetism, Oxford Univ. Press, Oxford, 1961. 